\title{
معالجة المعلومات وعلاقته بأداء المهارات الهجومية بكرة السلة لدى طلاب قسم التربية
}

\author{
الرياضية في جامعة زاخو \\ علي محمد احمد الزاخولي
}

قسم التربية الرياضية، فاكولتي التربية، جامعة زاخو ، اقليم كردستان-عيراق. Ali.al-zakholi@uoz.edu.krd)

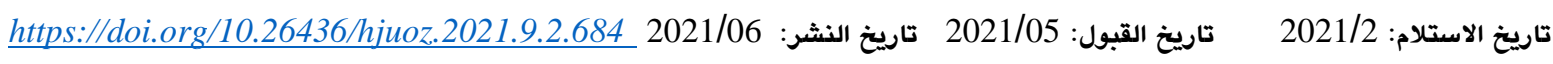

الملخص:

تكمن أهمية الدراسة الحالية في قدرة الطلاب على معالجة المعلومات وأيضا قدرة المتعلم على كيفية التعامل مع المعلومة التي يتلقاها من الدروس النظرية في الفهم والتركيز والتذكر والإدراك واعتماده على أنماط مختلفة من أجل التصنيف لهذه المعلومات وكذلك تحليلها

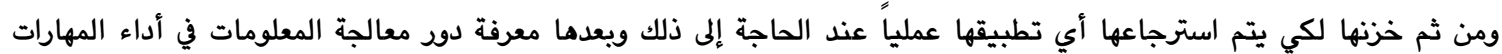

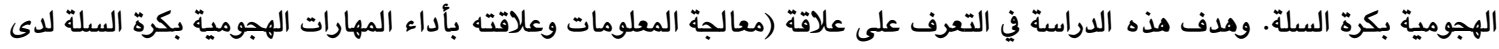

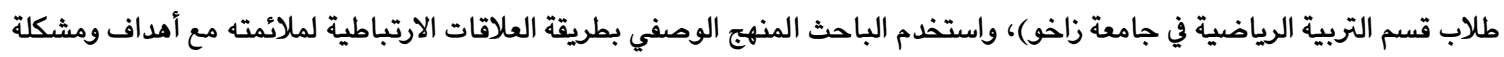

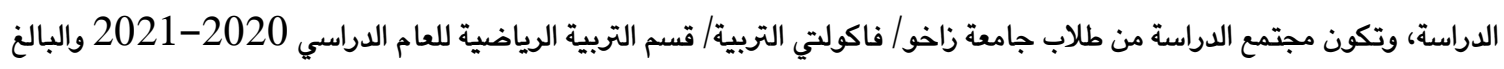

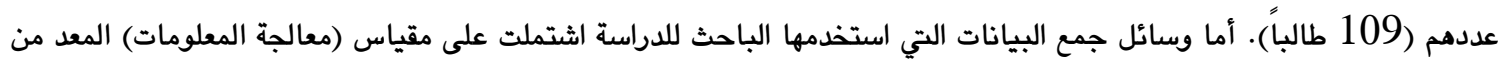

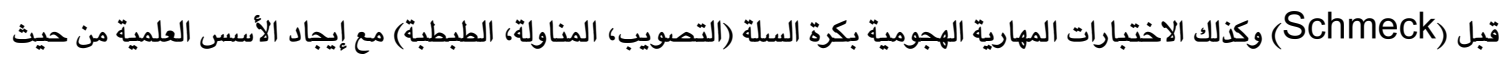

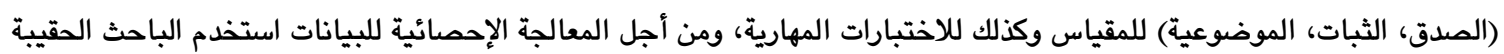

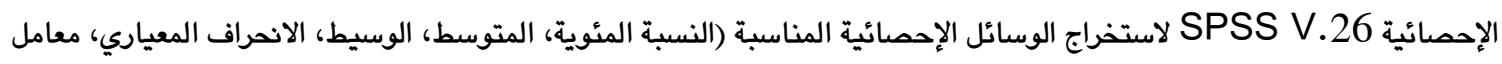
الالتواء التجانس معامل الارتباط سبيرمان، معامل الارتباط بيرسون) (ومن أهم الاستنتاجات التي توصل إليها الباحث هي (وجود علاقة ارتباط معنوية عالية بين معالجة المعلومات ومهارات التصويب والمناولة والطبطبة بكرة السلة) الكلمات الدالة: معالجة المعلومات، كرة السلة، التصويب، المناولة، الطبطبة.

"الحصول على الجانب النظري (النواحي المعرفية) بالنشاط الرياضي

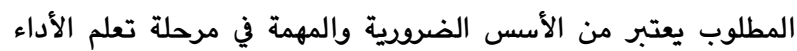
المهاري وذلك لكي تم ممارسة نشاط معين بالمستوى المطلوب ".

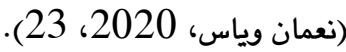
في الزمن الحالي ضرورة الاهتمام وبشكل متزايد من توفير والحصول على الجانب المعرفي للمهارة الرياضية وخصوصاً في المؤسسات

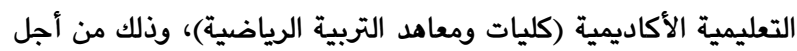
بناء أساس علمي صحيح ويتم العمل عليه وفق أسس ومبادئ علمية صحيحة لكي يتم الحصول على أداء عالي المستوى للمهارة الرياضية

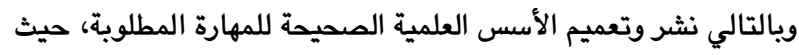

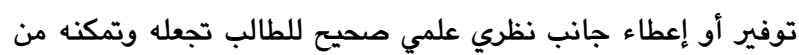
معرفة تفاصيل أجزاء المهارة، وضرورة تطوير هذه المهارة بالشكل

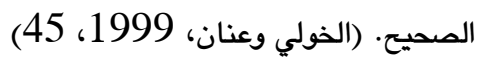
يتطلب من الطالب (الرياضي) أن يكون نشطاً وكذلك أن يكون فعالاً في

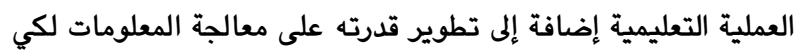

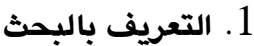

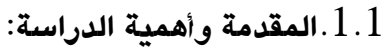

إن خلق البيئة التعليمة الرياضية المناسبة للطلاب تتطلب توفير معلومات مناسبة حول مفردات المادة التعليمية، إذ أن المعلومات المعرفية التي يتلقاها الطلاب أثناء عملية التعلم تتطلب منهم تحليلها بشكل جيد لكي تترجم إلى فعل حركي مناسب أداء مهاري جيد في الملعب. حيث أن أداء المهارة يعتمد بالأساس على كمية المعلومات التي يتلقاها الطلاب إضافة إلى تحليل هذه المعلومات بشكل ملائم ومناسب وذلك من أجل أن يكون الأداء للمهارة بالشكل المطلوب. ويالتالي فإن هذه العملية تحتاج إلى تنسيق عالي بين العمليات العقلية من حيث الفهم والاستيعاب والتذكر والادراك والتركيز وأيضاً إلى الأداء البدني للجسم أي أداء المهارة. حيث أن ضعف توفر المعلومات المرتبطة بالنواحي المعرفية تؤدي إلى ضعف الرغبة في تعلم المهارة أو تؤدي إلى أداء مهاري ضعيف. 
يكون قادراً على التنظيم بالإضافة إلى التطبيق للجوانب المعرفية بي 4.1. فروض الدراسة:

توجد علاقة ارتباط ذات دلالة إحصائية معنوية بين معالجة

المعلومات ومهارة التصويب بكرة السلة لدى عينة الدراسة. توجد علاقة ارتباط ذات دلالة إحصائية معنوية بين معالجة

المعلومات ومهارة المناولة بكرة السلة لدى عينة الدراسة. توجد علاقة ارتباط ذات دلالة إحصائية معنوية بين معالجة

المعلومات ومهارة الطبطبة بكرة السلة لدى عينة الدراسة.

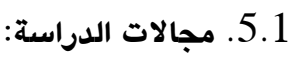

المجال البشري: طلاب قسم التربية الرياضية/ فاكولتي التربية/

جامعة زاخو.

المجال المكاني: القاعة الرياضية المغلقة لقسم التربية الرياضية،

$$
\text { والقاعات الدراسية. }
$$

المجال الزماني: 2021/1/4 ولغاية 2021/2/25

6.1

معالجة المعلومات: عملية مرتبطة بالجانب العقلي وتتم بمساندة الإحساس والإدراك وذلك تبعاً للجوانب المعرفية المخزونة في الذاكرة بالدماغ. (أبو حطب، 1983، 202)

المهارات الهجومية: هي حصيلة من المهارات (التصويب، المناولة، الطبطبة) يؤديها لاعب كرة السلة وذلك بعد استحواذه للكرة من أجل أداء مواقف اللعب المطلوية. (عبد الرحمن، 2000، 27)

2. الدراسات النظرية والدراسة المشابهة

1.2 - 1. الدراسات النظرية:

1.1.2

إن معالجة المعلومات مي نظرية علمية ظهرت في بداية الخمسينيات من القرن المنصرف، وهي عبارة عن قدرة الدماغ البشري لتحليل البيانات التي تم استلامها وترجمة هذه البيانات إلى أفعال في الزمن التي يطلبه الموقف المراد من ذلك، أي الأداء الفعلي (الحركي). (الزغلول،

وهذه النظري تعتمد بالأساس على تحليل الفرد للمعلومات المتلقات ويعدها إجراء سلسلة من المراحل لتحليل هذه المعلومات أو البيانات وهي خطوات يقوم بها الفرد أو الطالب باستقبال المعلومات ومن ثم

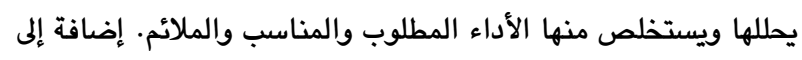
ذلك فإن قدرة الرد أو الطالب تعتمد بالأساس على الخبرات السابقة

ومنها الخبرات العلمية المرتبطة بالأداء. (عوض، 2002، 56) ومعالجة المعلومات تعتبر نظرية علمية مفادها أن ألفرد يتكون أدائه عبارة عن استقبال للمثير ومن ثم أدائها أي الاستجابة للمثير، والمثير
البيئة التي تحيطه لكي تسهل عليه عمليات الترميز للمعلومات المتلقات وتخزينها وأيضاً أن يكون قادراً على استرجاع المعلومة المطلوبة ويالوقت المطلوب عندما تكون الحاجة إلى ذلك، ويذلك يكون مستمراً في عملية التعلم. وإن المعالجة لهذه المعلومات تتم اعتماداً على مجموعة من الأسس المتوفرة في الدماغ البشري حيث يتم المعالجة للمعلومات التي تدخل إلى الدماغ بأنماط مختلفة وذلك من أجل أن يتم تحويلها إلى تمثيلات ويالتالي فإنه ينتج عن هذا مخرجات. وتعليم المهارات الهجومية بكرة السلة تتطلب تقديم وتوفير أكبر قدر ممكن من المدخلات، حيث انه كلما كانت المثيرات للعملية التعليمية

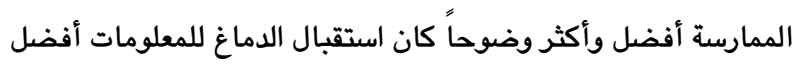
ويالتالي فإن مذا يؤدي إلى انتاج عملية تعليمية أفضل. ومهارات كرة السلة الهجومية تتميز بالسلوك الحركي السريع وذلك بسبب هدي اختلاف مواقف اللعب المختلفة إضافة على اختلاف مواقف اللاعب الخصم وايضاً حركات اللعب المطلوية. لذلك فإن أهمية الدراسة الحالية تكمن في قدرة المتعلمين على معالجة المعلومات وأيضا قدرة المتعلم على كيفية التعامل مع المعلومة التي يتلقاها في الفهم والتركيز والتذكر والإدراك واعتماده على أنماط مختلفة من أجل التصنيف لهذه المعلومات وكذلك تحليلها ومن ثم خزنها لكي يتم خزنها ثم استرجاعها عند الحاجة إلى ذلك ويعدها معرفة دود معالجة المعلومات في أداء المهارات الهجومية بكرة السلة.

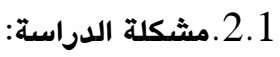

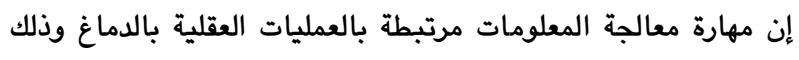
اعتماداً على الجانب النظري المخزون في الدماغ وهي كمية المعلومات المتلقات، حيث أن المعلومات النظرية مرتبطة بالدماغ بينما الأداء المهاري بكرة السلة مرتبط بالجانب البدني والقدرات الحركية للطالب، ويناءً على ذلك تكون مشكلة الدراسة من خلال التساؤلات التالية: هل باستطاعة الطالب أن يتلقى معلومات (الجانب النظري لمادة كرة السلة) وتطبيقها في الواقع (أداء عملي للمهارة).

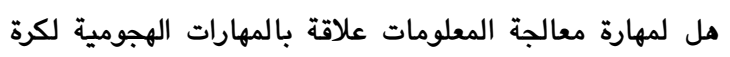
السلة لدى طلبة قسم التربية الرياضية، جامعة زاخو.

3.1 - 3.1 أهداف الدراسة:

التعرف على درجة العلاقة بين معالجة المعلومات ومهارة

التصويب بكرة السلة لدى طلبة قسم التربية الرياضية، جامعة زاخو. التعرف على درجة العلاقة بين معالجة المعلومات ومهارة المناولة بكرة السلة لدى طلبة قسم التربية الرياضية، جامعة زاخو. التعرف على درجة العلاقة بين معالجة المعلومات ومهارة الطبطبة بكرة السلة لدى طلبة قسم التربية الرياضية، جامعة زاخو. 
4.1.2 هي عملية توجيه الكرة من قبل اللاعب المستحوذ على الكرة إلى سلة

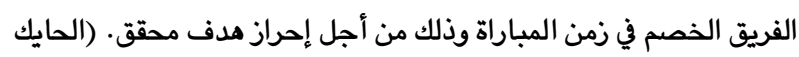

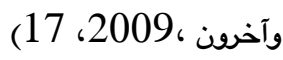
وتحدد نتيجة المباراة النهاية في لعبة كرة السلة اعتماداً على التصويبات

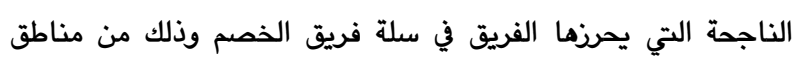
مختلفة من الملعب. (الزاخولي، 2019، 53

5.1.2 5 المناولة: هي عملية يقوم بها أعضاء أو لاعبي الفريق بتبادل وتوجيه الكرة فيما

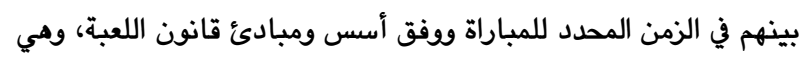
مهارة مهمة إذ يجب على اللاعب إتقان هذه المهارة حيث لها أهمية في

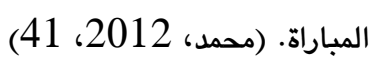

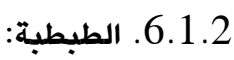
هي تحرك لاعب كرة السلة بتنطيط الكرة داخل الملعب وفق قانون اللعبة، حيث يحق للاعب حامل الكرة بالتحرك داخل الملعب ويأي اتجاه

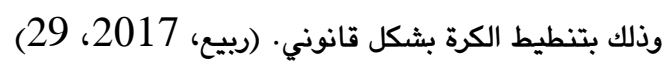

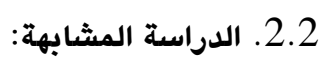
دراسة ياس ونعمان (2020): معالجة المعلومات وعلاقته بأداء مهارتي الاعداد واستقبال الارسال بالكرة الطائرة للطالبات. هدفت الدراسة إلى:

التعرف على العلاقة بين معالجة المعلومات ومهارة الاعداد بالكرة. التعرف على العلاقة بين معالجة المعلومات ومهارة استقبال

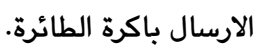

وتكون عينة الدراسة من (21) طالبة وينسبة (19,81 19 ) من المجتمع الأصل المتكون من (106) طالبة، وتم اختيار العينة بالطريقة العشوائية.

والاستنتاجات التي توصل اليها الباحثان: ان المتعلمات لديهن القدرة على معالجة المعلومات المقدمة لهن. ان لمعالجة المعلومات دود في أداء مهارة استقبال الارسال بالكرة

تساهم معالجة المعلومات ويشكل إيجابي في أداء مهارة الاعداد

بالكرة الطائرة.

مناقثة الدراسة السابقة: عمل الباحثان على تطبيق الدراسة على الطالبات (إناث) بنسبة (19.81\%) من مجتمع الدراسة لمهارتي كرة الطائرة. بينما الدراسة الحالية تم تطبيقها على الطلاب (ذكور) ومحاولة أخذ المجتمع كاملاً قدر الإمكان، وكذلك في هذه الدراسة تم التعامل مع فعالية رياضية مختلفة وهي لعبة كرة السلة ومهاراتها الهجومية.
عبارة عن المعلومات والبيانات التي يستلمها دماغ الفرد (الجانب النظري لأداء المهارة)، وكيفية استطاعة الفرد أو الطالب على تحليل مذه المعلومات وفق قدرة دماغه، وقدرة الدماغ تقاس بخبرة وتجارب الطالب السابقة والمتراكمة. (قطامي وقطامي، 2000، 67) ويعد تحليل مذه المعلومات تتكون لدى الفرد قدرة بحيث متى تتطلب الموقف أداء مهارة معينة، فإن الطالب يؤدي هذه المهارة اعتماداً على تلى فئكي كمية المعلومات المخزنة في الذاكرة وسرعة استرجاعها. (السلوم، (59) 2001 لذلك فإن الأداء المهاري تعتمد على معالجة المعلومات التي يكتسبها الفرد في الفترات السابقةـ إذا فهي حلقة الوصل بين المعلومات المستلمة لدماء (الجانب النظري) واسترجاع مذه المعلومات وترجمتها إلى أفعال حركية

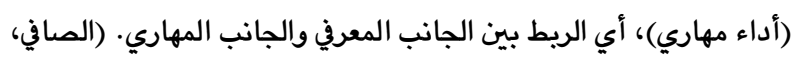
(138، 2000

2.1.2. استراتيجيات التدريس المعتمدة على أساس نظرية معالجة المعلومات: • معتراتيجية الانتباه والتركيز: وهي عملية يقوم بها الفرد اعتماداً على التركيز والإدراك على مثير ما بين مجموعة من المثيرات

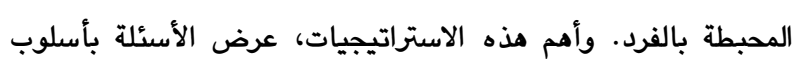
واضح، عرض مفهوم الدرس وإظهار أهدافه، استخدام أساليب مختلفة في عرض المعلومة المرتبطة بالمادة العلمية، والابتعاد عن مصادر تشتت التران

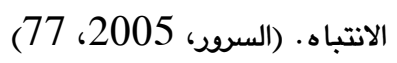
استراتيجية الترميز والتذكر: وتعتبر التميز عملية يتم فيها تحول المعلومات المكتسبة كالأصوات والصور إلى رموز بشكل يقلها الدماغ. وهي خطط المتجهة إلى التذكر، والتي تساند الفرد على تنظيم وتحليل البيانات لغرض تطوير قدرة دماغ الفرد على الاسترجاع. (الذهبي، 2005، 87) • استراتيجية التخزين: وهي قدرة الدماغ على تخزين المعلومة في الذاكرة طويل الأمد، إضافة إلى ذلك تقوم بتكوين ملف دائم لها وقابل للاسترجاع في اللحظة المناسبة. (الجبوري، 2005، 32 هاستراتيجية الاسترجاع: تتم هذه العملية وفق ثلاث مراحل، وهي مرحلة تنقيب المعلومات، ومرحلة لم وتصنيف المعلومات، ومرحلة الأداء المتعلق بالذاكرة. (جابر، 2006، 5رحلب المعات، ومرحة 3.1.2. المهارات الهجومية بكرة السلة: إن الغرض من عملية الهجوم في للعبة كرة السلة هي معرفة ضعف الفريق المنافس أو الأخطاء التي يرتكبها الفريق الخصم في العملية الدفاعية التي يقوم بها واستغلالها وإحراز النقاط في سلته. ولعبة كرة السلة

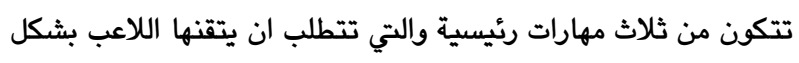
جيد حتى يتمكن من أداء اللعبة بشكل جيدة، وهذه المهارات هي

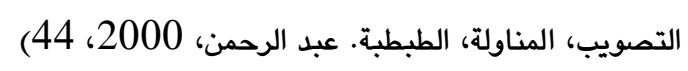


دراسة الغريري، عطية (2006) (المعالجة المعلوماتية وعلاقتها

بالذكاء لدى طلبة كلية المعلمين)

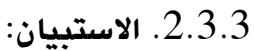

يعتبر الاستبيان من الأدوات الأكثر استخداما من حيث جمع المعلومات والبيانات في الدراسات العلمية التي تتطلب الوصول إلى آراء وأجوية

$$
\text { العينة والأفراد. (دويدري، 2000، }
$$

قام الباحث بإعداد مجموعة من الاستبيانات للوصول إلى غاية

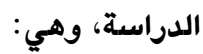
استمارة الاستبيان يضم المقياس (الملحق رقم 5) والذي تم عرضه على مجموعة من الخبراء والمتخصصين (الملحق رقم 1) وذلك من أجل تحديد مدى ملائمة تطبيق المقياس على عينة الدراسة. استمارة استبيان (الملحق رقم 2) والذي تم عرضة على مجموعة من الخبراء والمتخصصين في مجال كرة السلة (الملحق رقم 3) من أجل تحديد أنسب الاختبار المراد تطبقها على عينة الدراسة.

3.3.3. الاختبارات: يعتبر الاختبار أداة من أجل قياس قدرة الفرد لمهارة معينة أو صفة بدنية معينة. (الفرطوسي وآخرون، 2015، 17) ولغرض الوصول إلى الغاية من الدراسة تم تحديد مجموعة من الاختبارات المهارية بكرة السلة (الملحق رقم 2) وعرضت على مجموعة من السادة الخبراء والمتخصصين بكرة السلة (الملحق رقم 3)، وتم اختيار أنسب الاختبارات، والجدول رقم (2) يبين النسبة المئوية المختارة للمهارات الهجومية بكرة السلة وحسب ترتيب نسبها: الجدول رقم (2) يبين النسبة المئوية المختارة للمهارات الهجومية بكرة السلة

\begin{tabular}{|c|c|}
\hline النسبة المئوية & الاختبار \\
\hline $85 \%$ & التصويب الأمامي من القفز \\
\hline $85 \%$ & المناولة الصدرية \\
\hline $71 \%$ & الطبطبة السريعة (4 شواخص) \\
\hline $62 \%$ & التصويب من ثلاث نقاط (60 ث) \\
\hline $55 \%$ & التصويب الأمامي \\
\hline $43 \%$ & مناولة حائط الارتداد \\
\hline $42 \%$ & مناولة نلسون \\
\hline $37 \%$ & الطبطبة السريعة بتغيير الاتجاه \\
\hline $25 \%$ & الطبطبة المكوكية \\
\hline
\end{tabular}

تم الاعتماد على المهارة الهجومية بكرة السلة في الجدول رقم (2) التي اكتسبت نسبة اتفاق من السادة الخبراء والمتخصصين أعلى من

\section{3. منهج الدراسة وإجراءاتها الميدانية}

$$
\text { 1.3 منهج الدراسة: }
$$

استخدم الباحث المنهج الوصفي بأسلوب العلاقات الارتباطية، كونه ملائم لطبيعة مشكلة الدراسة وأهدافها. 2.3. المجتمع وعينة الدراسة:

تمثل مجتمع الدراسة الحالية بطلاب قسم التربية الرياضية في فاكولتي التربية بجامعة زاخو للعام الدراسي (2021-2020)، والبالغ عددهم (109) طالباً. ويمثلون المراحل الدراسية الأربعة. أما عينة الدراسة تمثلت بطلاب المرحلة (الثانية، والثالثة، والرابعة) والبالغ عددهم (79) طالباً وينسبة مئوية (.72.47). واختير المراحل الثلاثة بالطريقة العمدية، وذلك بعد استبعاد ثلاثة طلبة أدوا التجربة الاستطلاعية، وتم ايضاً استبعاد طلاب المرحلة الأولى كونهم حديثي الالتحاق بالقسم ولم يأخذوا مواد دراسية (مواد نظرية) كافية كونهم في بداية السنة الدراسية الجديدة. كما مو موضح في الجدول رقم

جدول رقم (1) يبين النسبة المئوية وعدد الطلاب لعينة الدراسة

\begin{tabular}{|c|c|c|c|}
\hline النسبة المئوية من مجتمع & عدد الطلاب & 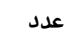 & مجموع \\
\hline الدراسة & المستبعدين & الطلاب & الطلاب \\
\hline$\% 72.47$ & 30 & 79 & 109 \\
\hline
\end{tabular}
جدول يبين مجتمع البحث وعينته

3.3. وسائل جمع البيانات والمعلومات: 1.3.3. تحليل المحتوى: الباحث يقوم بتحليل متغيرات الدراسة المراد قياسها اعتماداً على خبرته المرتبطة بالتخصص المعنى وكذلك من خلال مراجعة المراجع والمصادر والدراسات العلمية المتعلقة بالاختصاص المعني. (مجيد وسلمان، 1992، 192، 12 ولغرض الحصول على البيانات الدقيقة والمعلومات المرتبطة بموضوع الدراسة الحالية، قام الباحث بتحليل محتوى العديد من المراجع والمصادر والدراسات العلمية لكي تتضح الرؤية بشكل أفضل، ومنها: دراسة المبارك، سليمان (2009) (المعالجة المعلوماتية وعلاقتها بالدافع المعرفي لدى طلبة كلية التربية الأساسية في جامعة موصل). دراسة الرفوع، محمد (2008): (أساليب معالجة المعلومات لدى طلبة المرحلة الثانوية الأكاديمية في الأردن وعلاقتها بالجنس مله معائ والتخصص)

$$
\text { المرجع الزغلول، عبد الرحيم (2012) (نظريات التعلم). }
$$


المعالجة المفصلة والموسعة (المحور الراب): يتكون من

\section{$\bullet$}

(14) فقرة، وهذا المحور مختص بقدرة الطالب بزيادة المادة الدراسية

وذلك بإضافاته الخاصة ومحاولاته القيام بالتعبير عن الأفكار المتعلقة وفذرة بالجانبي العلمي ويأسلويه الخاص.

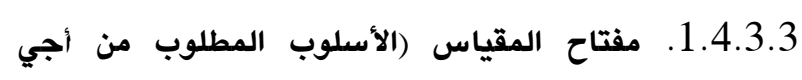
تصحيح المقياس):

اعتمد الباحث على أسلوب شمك (Schmeck) من أجل تصحيح المقياس وذلك اعتمادا على المدرج الثنائي للاستجابة (تنطبق علي) و (لا تنطبق علي)، بواقع إعطاء الونن (1) للإجابة على الفقرة (تنطبق علي)، وإعطاء الوزن (0) للفقرة (لا تنطبق علي) المتعلقة بالفقرات

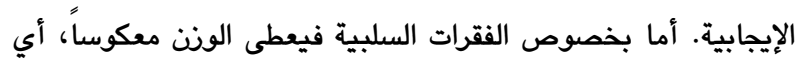
بشكل إعطاء الونن (0) للفقرة (تنطبق علي) وإعطاء الونن (1) للفقرة

$$
\text { (لا تنطيق علي). }
$$

\section{3. التجربة الاستطلاعية:}

لكي يتم الحصول على البيانات المرتبطة بعينة الدراسة، يجب أولا التأكد من سلامة المقياس وكذلك سلامة الاختبارات وطرق إجرائها، لذلك ويتاريخ 2021/1/26 تم تطبيق المقياس على عينها وعددها (3) وتمثل مجتمع الدراسة، وكذلك بتاريخ 2021/1/27 تطبيق الاختبارات المهارية الهجومية بكرة السلة، من أجل تحقيق بعض ولدئ الأهداف العلمية والإدارية.

5.3. الأسس العلمية للمقياس والاختبارات: إن الأسس العلمية ضرورية لجميع المقاييس والاختبارات وذلك من أجل الإل الحصول على نتائج يمكن الاعتماد عليها من أجل التعميم. (العجيلي،

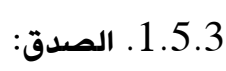
صدق الاختبار هو قدرة الاختبار على القيام بقياس ما وضعه من أجله. (أبو مغلي وسلامة، 2010،41) • صدق المقياس (مقياس معالجة المعلومات): قام الباحث بعرض المقياس على عدد من الخبراء والمتخصصين (الملحق رقم 1) من حيث ملائمة المقياس مع ظرف عينة الدراسة

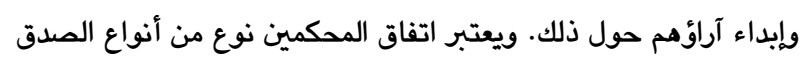
الظاهري، ويذلك تم تحقيق الصدق للمقياس. صدق الاختبارات (اختبارات المهارات الهجومية بكرة

السلة):

قام الباحث بعرض الاختبارات على عدد من الخبراء والمتخصصين بمجال كرة السلة (الملحق رقم 2) من حيث اختيار أنسب الاختبارات للمهارات الهجومية بكرة السلة وملائمتها مع ظروف عينة الدراسة وإبداء
1.3.3.3. الاختبارات المهارية الهجومية المستخدمة في

الدراسة: - الد:

$$
\begin{array}{r}
\text { اختبار التصويب الأمامي من القفز. (الملحق رقم 5) } 1 \text { اختبار المناولة الصدرية. (الملحق رقم 6) } \\
\text { (الطبطبة السريعة (4 شواخص). (الملحق رقم 7) }
\end{array}
$$

4.3.3. المقياس المستخدم في الدراسة (مقياس معالجة

المعلومات): (المات

قام الباحث بمطالعة ومراجعة المراجع والدراسات العلمية لغرض إيجاد

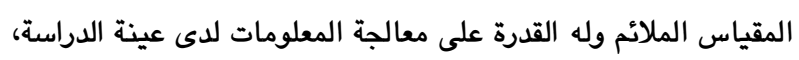
ووجد مقياس شمك (Schmeck) لقياس معالجة المعلومات والمترجم إلى اللغة العربية حيث تم إستخدام المقياس في عدد من الدراسات (عداي،

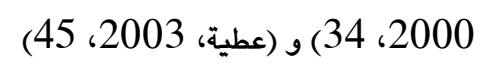
وتم أخذ المقياس من دراسة نعمان وياس (2020)، حيث تم تطبيق المقياس على طالبات كلية التربية الرياضية بجامعة بغداد، وذلك بعد استخراج الأسس العلمية للمقياس من حيث الصدق والثبات والموضوعية. (نعمان وياس، 2020، 44) وقام البحث بعرض المقياس على عدد من الخبراء والمتخصصين من أجل معرفة ملائمة المقياس وتعديل فقراتها إن لزم الأمر (الملحق رقم 1). وقام الباحث بترجمة المقياس المتعلق بإجابات الطلبة إلى اللغة

$$
\text { الكوردية. (الملحق رقم 4) }
$$

والمقياس متكون من (62) فقرة من أجل تحديد الأبعاد لمعالجة المعلومات، ومصنفة إلى أربعة محاور، وهي: • المعالجة العميقة (المحور الأول): يتكون من (18) فقرة مرتبط المحور بكيفية تنظيم الطالب أو الطالبة للمعلومات المتعلقة

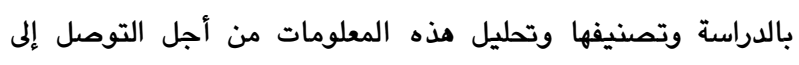
استيعابها بالشكل العميق والدقيق ويعدها العمل على تقويم هذه المعلومات وأيضا نقدما، ويتكون المحور من عشر فقرات سلبية وثماني فقرات إيجابية.

الدراسة المنهجية (المحور الثاني): يتكون من (23) فقرة بواقع ثلاث فقرات سلبية وعشرون فقرة إيجابية، وهذا المحور هو من أجل كيف ينظم الطالب وقته وأيضاً جهده والقيام بمذاكرة المادة النظرية والاستعداد للامتحان. • الاحتفاظ بالحقائق العلمية (المحور الثالث): يتكون من (7) فقرات، بواقع فقرتين إيجابية وخمسة فقرات سلبية، وهذا المحور متعلق بقدرة الطالب على تخزين المعلومات المتعلقة بالمادة الدراسية في الدماغ والقدرة على استرجاع هذه المعلومات بشكل فعال وذلك عند

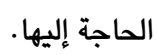




\begin{tabular}{l|l|l|l|l}
\hline 0.82 & 0.14 & 5.01 & 5.021 & $\begin{array}{c}4(\text { الطبطبة السريعة } \\
\text { (شواخص }\end{array}$ \\
\hline
\end{tabular}

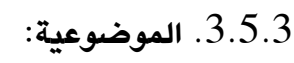

يعتبر الاختبار موضوعياً، وذلك عندما لا تتأثر نتائج الاختبار بذات

المقيم. (عويس، 1999، 53:

$$
\text { موضوعية المقياس: }
$$

إن قياس المقياس كان عن طريق عرض المقياس على العينة، ويذلك

العينة تختار الإجابة للفقرة المطلوية.

$$
\text { موضوعية الاختبارات: }
$$

إن القيام بقياس الاختبارات كان عن طريق استخدام الأجهزة وأدوات عالية الموضوعية (ساعات التوقيت، شريط قياس)

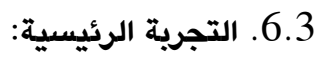
بعد التأكد من سلامة المقياس والاختبارات، تم تطبيق التجربة الرئيسة على عينة الدراسة بالشكل الآتي: بتاريخ 2021/2/15 تم تطبيق المقياس على عينة الدراسة. وذلك في القاعات الدراسية لقسم التربية الرياضية في فاكولتي التربية بجامعة زاخو ويتمام الساعة 9:00 تم تنفيذ الإجابة على المقياس من قبل الطلبة ووفق الوقت الزمني المحدد لذلك، بعدها تم جمع جميع الاستبيانات من قبل الباحث وذلك من أجل تفريغها ومعالجتها إحصائياً. بتاريخ 2021/2/16 تم تطبيق الاختبار على عينة الدراسة. ثم تطبيق الاختبارات حيث تم لم الطلبة في القاعة الرياضية المغلقة لقسم التربية الرياضية في فاكولتي التربية بقسم التربية الرياضية، ويتمام الساعة 9:00 صباحاً تم ذلك. حيث تم تسجيل نتائج الاختبارات في القوائم المعدة مسبقا لذلك ويعدما تفريخ مذه البيانات ومن ثم معالجتها إحصائياً. حيث كل مقياس (الاستبيان) توجد فقرة وهي اسم الطالب، وكذلك تسجيل بيانات الاختبارات المهارية لكل طالب حسب اسمه وحسب الاستمارة المعدة لذلك، ووضع درجة مقياس كل طالب أمام درجة اختباراته المهارية وذلك من أجل استخراج العلاقة الارتباطية. 7.3 الأجهزة والأدوات المستخدمة: ساعة إلكترونية للتوقيت.

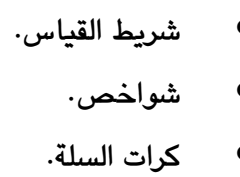

2 تم تطبيق معامل الارتباط سبيرمان لإيجاد قيمة الثبات وذلك كون عينة الثبات عددها عشرة ويالتالي فإنها تعتبر من ضمن الإحصاء اللامعلمي
آراؤهم حول ذلك. ويعتبر اتفاق المحكمين نوع من أنواع الصدق الظاهري، ويذلك ثم تحقيق الصدق للاختبارات.

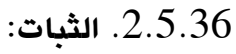

المقصود بالثبات هو أن تكون أدوات القياس ذو قدرة ودرجة عالية من الدقة والاتساق والإتقان بخصوص البيانات التي يتم تزويدنا به عن ان بـون سلوك أفراد العينة. (الجلبي، 2005، 113) ثبات المقياس (مقياس معالجة المعلومات): ولغرض الحصول على درجات الثبات للمقياس تم تطبيق المقياس على عينة من مجتمع الدراسة وعددهم ثلاثة طلاب، ويعد فترة زمنية قدرها اسبوعان تم إعادة تطبيق نفس المقياس على العينة نفسها وتحت

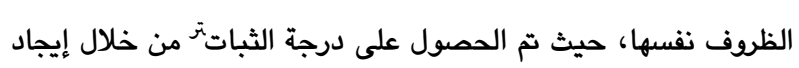
معامل الارتباط (العلاقة) بين درجات المقياس الأول ودرجات المقياس الثاني. والجدول رقم (3) يبين قيمة معامل الثبات لمقياس معالجة

\begin{tabular}{|c|c|c|c|c|}
\hline قيمة & الانحراف & الوسيط & المتوسط & المقياس \\
\hline 0.84 & 2.94 & 45 & 45 & المعلومات \\
\hline
\end{tabular}
المعلومات.

\section{ثبات الاختبارات (الاختبارات المهارية الهجومية بكرة}

السلة):

ولغرض الحصول على درجات الثبات للاختبارات المهارية الهجومية بكرة السلة تم تطبيق الاختبارات على عينة من مجتمع الدراسة وعددهم عشرة طلاب (طلاب المرحلة الأولى - المستبعدين من الدراسة)، ويعد فترة زمنية قدرها اسبوعان تم إعادة تطبيق نفس الاختبارات على العينة

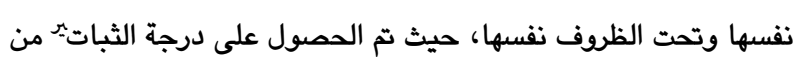
خلال إيجاد معامل الارتباط (العلاقة) بين درجات الاختبار الأول ودرجات الاختبار الثاني. والجدول رقم (4) يبين قيمة معامل الثبات للاختبارات المهارية الهجومية بكرة السلة.

\begin{tabular}{|c|c|c|c|c|}
\hline \multicolumn{5}{|c|}{ الهجومية بكرة السلة } \\
\hline قالثبات & المعياري & | الوسيط & المتوسط & الاختبار \\
\hline 0.80 & 1.03 & 8 & 8.2 & التصويب الأمامي من \\
\hline 0.85 & 13.19 & 161.5 & 162.3 & المناولة الصدرية \\
\hline
\end{tabular}
الجدول رقم (4) يبين قيمة معامل الثبات للاختبارات المهارية

1 عددها عشرة ويالتالي فإنها تعتبر من ضمن الإحصاء اللامعلمي 
معامل الارتباط سبيرمان (العلاقة).

$$
\text { معامل الارتباط بيرسون (العلاقة). }
$$

4. عرض النتائج وتحليلها ومناقشة متغيرات الدراسة

$$
\text { 1.4 }
$$

1.1.4. عرض وتحليل نتائج المعامل الإحصائية لمتغيرات

$$
\text { الدراسة: }
$$

\begin{tabular}{|c|c|c|c|c|c|}
\hline $\begin{array}{c}\text { (التجانس) معامل } \\
\text { الالتواء }\end{array}$ & المعياري & الوسيط & $\begin{array}{l}\text { المتوسط } \\
\end{array}$ & الدرجة & المتغير \\
\hline 1.27 & 2.54 & 44 & 44.29 & درجة & معالجة المعلومات \\
\hline 0.70 & -1.20 & 6 & 6.10 & نقطة & التصويب \\
\hline 0.31 & 1.96 & 161 & 161.05 & تكرار & المناولة \\
\hline-0.5 & 0.3 & 5.04 & 5.03 & ثانية & الطبطبة \\
\hline
\end{tabular}

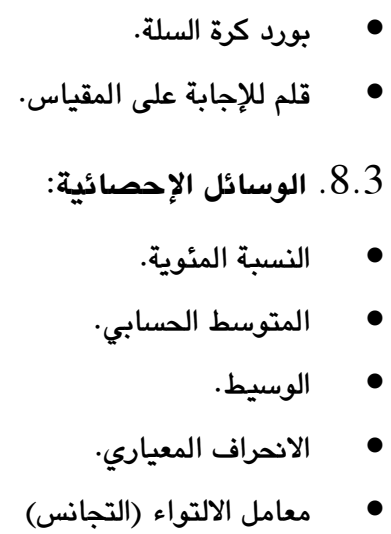

جدول رقم (5) يبين المعامل الإحصائية لمتغيرات الدراسة

\begin{tabular}{|c|c|c|c|c|}
\hline الدلالة & Sig. & قيمة (ر) & \multicolumn{2}{|c|}{ المتغيرات } \\
\hline معنوي - قوي جداً & 0.000 & $* * 0.82$ & مهارة التصويب & معالجة المعلومات \\
\hline
\end{tabular}

2.1.4 عرض وتحليل نتيجة العلاقة (الارتباط) بين متغيري معالجة المعلومات ومهارة التصويب:

معنوي عند مستوى الدلالة (0.05)

Sig.

يتبين من الجدول رقم (6) أن قيمة العلاقة (قيمة الارتباط) بين متغيري يوجد ارتباط عالي وذو قيمة معنوية بين المتغيرين.

\begin{tabular}{|c|c|c|c|c|}
\hline الدلالة الد & Sig. & قيمة (ر) & \multicolumn{2}{|c|}{ المتغيرات } \\
\hline معنوي - قوي جداً & 0.000 & $* * 0.81$ & مهارة المناولة & معالجة المعلومات \\
\hline
\end{tabular}
معالجة المعلومات ومهارة التصويب بلغت (0.82**)، وأن قيمة 3.1.4. عرض وتحليل نتيجة العلاقة (الارتباط) بين متغيري معالجة المعلومات ومهارة المناولة:

أقل من مستوى الدلالة (0.05)، ويالتالي فهذا يدل على أنه يوجد

$$
\text { يتبين من الجدول رقم (7) أن قيمة العلاقة (قيمة الارتباط) بين متغيري ارتباط عالي وذو قيمة معنوية بين المتغيرين. }
$$

\begin{tabular}{|c|c|c|c|c|}
\hline الدلالة & Sig. & قيمة (ر) & \multicolumn{2}{|c|}{ المتغيرات } \\
\hline معنوي - قوي جدا & 0.000 & $* * 0.84$ & مهارة الطبطبة & معالجة المعلومات \\
\hline
\end{tabular}

معالجة المعلومات ومهارة المناولة بلغت (0.81***)، وأن قيمة .4ig S.1.4. عرض وتحليل نتيجة العلاقة (الارتباط) بين متغيري

معالجة المعلومات ومهارة الطبطبة:

جدول رقم (8) يبين نتيجة العلاقة (الارتباط) بين متغيري معالجة والمعلومات مهارة الطبطبة 
إجراء دراسات معالجة المعلومات على عينات أخرى (طالبات).

إجراء دراسات مشابه على عينات المراحل الدراسية الإعدادية).

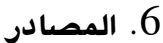

1

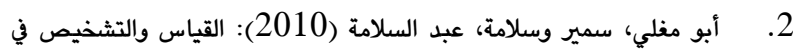
التربية الخاصة، دار اليازودي للطباعة والنشر، عمان.

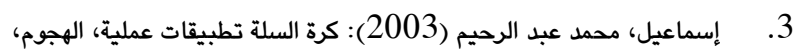
الجزء الأول، الطبعة الثانية، منشأ المعارف، الإسكندرية.

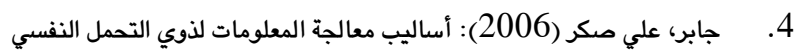

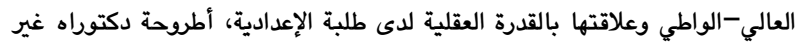

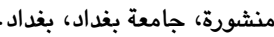
5. الجبوري، راضي حسن عبيد (2005): أساليب معالجة المعلومات وعلاقتها بقدرات التفكير، رسالو ماجستير غير منشورة، جامعة بغداد، بغداد. 6.

النفسية والتربوية، موسوعة علاء الدين للطباعة والنشر، دمشق. 7. الحايك، صادق وآخرون (2009): أثر برنامج تدريبي مقترح لتطوير مهارة

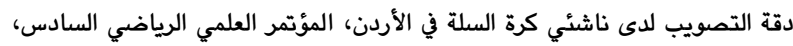

المجلد الثاني، كلية التربية الرياضية، الجامعة الأردنية، عمان. 8. حسن، عمار عبد الرحمن (1998): مستويات الضغوط النفسية وعلاقتها

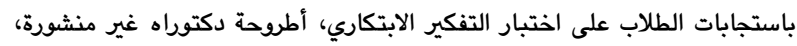
معهد الدراسات والبحوث التربوية، جامعة القاهرة. 9. الخولي، أمين وعنان، محمود (1999): المعرفة الرياضية، دار الفكر العربي،

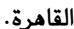
10. دويدري، رجاء وحيد (2000): البحث العلمي أساسياته النظرية وممارساته العلمية، دار الفكر العربي، دمشق.

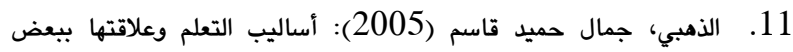
المتغيرات، مجلة البحوث النفسية والتربوية، العدد (5)، جامعة بغداد، بغداد.

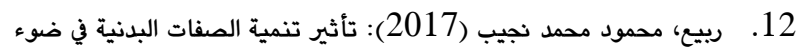

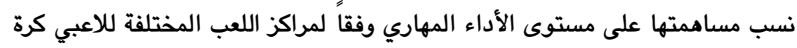
السلة، أطروحة دكتوراه غير منشورة، كلية التربية الرياضية للبنين، بنها. 13. الزاخولي، علي محمد احمد (2019): تحليل معاملي الثبات والصدق على دئى وفقد درجة التجانس لبعض الاختبارات البدنية والمهارية بكرة السلة، رسالة ماجستير غير منشورة، جامعة دهوك، كلية التربية البدنية وعلوم الرياضة، دهوك. 14. الزغلول، عماد عبد الرحيم (2010): نظريات التعلم، دار الشروق، عمان.

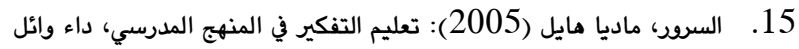
للطباعة والنشر، عمان. 16. السلوم، عبد الحكيم (2001): التفكير وحل المشكلات، مجلة النبأ للمستقبل والثقافة والاعلام، العدد 53، بيروت. 17. الصافي، عبد الله بن طه (2000): الفروق في استراتيجيات معالجة المعلومات في ضوء متغيري التخصص والتحصيل الدراسي، مجلة العلوم الإنسانية والإدارية، المجلد الأول، العدد 1، جامعة الملك فيصل، الأحساء.

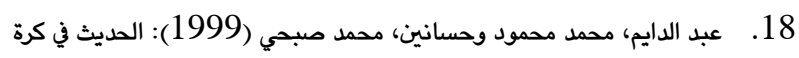

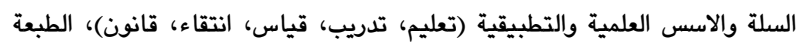
الثانية، دار الفكر العربي، القاهرة.

\section{معنوي عند مستوى الدلالة (0.05)}

يتبين من الجدول رقم (8) أن قيمة العلاقة (قيمة الارتباط) بين متغيري Sig. معالجة المعلومات ومهارة الطبطبة بلغت (0.84***)، وأن قيمة أقل من مستوى الدلالة (0.05)، ويالتالي فهذا يدل على أنه يوجد ارتباط عالي وذو قيمة معنوية بين المتغيرين. 2.4 من خلال الجداول (6، 7، 8) يتبين أن عينة الدراسة الحالية لها قدرة جيدة في تحليل المعلومات التي تحصل عليها من البيئة التعليمية التي تدرس فيها وينعكس ذلك من خلال تحويل مذه المعلومات إلى واقع حال (أي تحويل المعلومات أو الجانب النظري المكتسب من الدروس النظرية إلى أداء مهاري في ملعب كرة السلة)، ويعزو الباحث ذلك السبب إلى كثرة إعطاء الطالب الدروس النظرية خلال مراحل الدراسة الجامعية ولمختلف المواد العلمية وهذا ما يؤكده (حسن، 1998، 19) "إن تعرض الطالب للمواد الدراسية خلال مرحلة الجامعة ويشكل مستمر تطور لديه

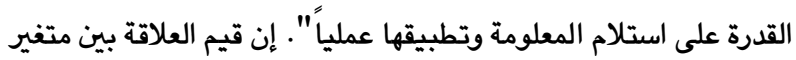
الدراسة معالجة المعلومات ومهارات كرة السلة (التصويب، المناولة، الطبطبة) كانت العلاقة ذو قيم دلالة إحصائية معنوية عالية على الرغم من التفاوت بين درجات العلاقة ويعز الباحث ذلك السبب إلى أن قدرة الفرد في تعلم مهارة كرة السلة واكتسابها وتطويرها مرتبط بالجانب المعرفي الذي يكتسبه الفرد في المراحل التعليمية السابقة حيث كلما كان الفرد ذو مخزون معرفي جيد عن مامرةٍ ما كلما امتلك سرعة في التعلم والإتقان لتلك المهارة وهذا ما يؤكدهُ إسماعيل (2009): "يفضل أن يمتلك اللاعب الجوانب النظرية قبل أن يتعلم ممارسة كرة السلة، حيث هذه الخطوة ستمكنه من أن يتعلم مهارة كرة السلة بسرعة وكما ستؤله إلى أن تتطور هذه المهارة لديه في حال الاستمرار على التعلم والتمرين".

(إسماعيل، 2003، 65، (إن)

\section{5. الاستنتاجات والتوصيات}

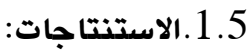

وجود علاقة ارتباط معنوي بين معالجة المعلومات ومهارة

التصويب بكرة السلة.

وجود علاقة ارتباط معنوي بين معالجة المعلومات ومهارة

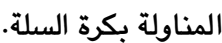

وجود علاقة ارتباط معنوي بين معالجة المعلومات ومهارة

الطبطبة بكرة السلة.

2.5 - 2.5 التوصيات:

إجراء دراسات معالجة المعلومات لفعاليات رياضية أخرى 
25. عويس، خير الدين علي (1999): دليل البحث العلمي، دار الفكر العربي، القاهرة.

26. الفرطوسي، علي سموم وآخرون (2015): القياس والاختبار والتقويم في المجال الرياضي، دار الكتب والوثائق، بغداد.

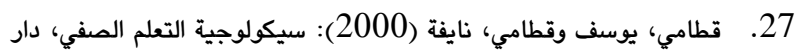
الشرقق، عمان. 28. مجيد، ريسان خريبط وسلمان، ثائر داود (1992): طرق تصميم بطاريات الاختبار والقياس في التربية الرياضية، مطبعة دار الحكمة، البصرة.

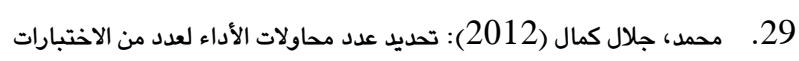
البدنية والمهارية بكرة السلة على وفق الأسس العلمية لبعض الفئات العمرية، أطروحة دكتوراه غير منشورة، جامعة دموك، كلية التربية الرياضية، دهوك. 30. نعمان، مواهب حميد وياس، تمارة أحمد (2020): معالجة المعلومات وعلاقته بأداء مهارتي الاعداد واستقبال الارسال بالكرة الطائرة للطالبات، المجلة الرياضية المعاصرة، المجلد 19، العدد 1، جامعة بغداد، بغداد.
19. عبد الرحمن، عبد الرحمن خليل (2000): تأثير تنمية الأداء التكتيكي

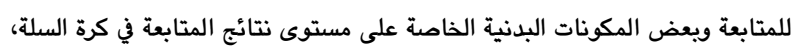

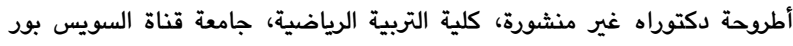
20. العجيلي، صباح حسين حمزة (2005): القياس والتقويم التربوي، الطبعة الثالثة، مكتبة التربية للطباعة والنشر، صنعاء. 21. عداي، عبد الزهرة لفتة (2000): أساليب معالجة المعلومات وعلاقتها بأنماط

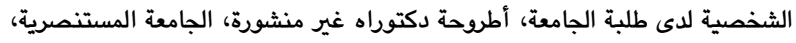
كلية التربية، بغداد. 22. عطية، سعد جاسم (2003): أثر برنامج استراتيجية معالجة المعلومات في التحصيل الدراسي وانتقال أثر التدريب لطلبة كلية المعلمين بحسب مستوى ذكائهم، أطروحة دكتوراه غير منشورة، جامعة بغداد، كلية التربية، بغداد.

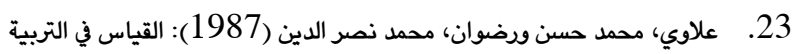
الرياضية وعلم النفس، دار الفكر العربي، القاهرة.

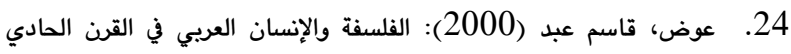
والعشرين، المؤتمر الفلسفي العربي الثاني لبيت الحكمة، بيت الحكمة، بغداد. 
الملاحق:

الملحق رقم (1) قائمة أسماء للسادة الخبراء والمتخصصين التي ثم عرض المقياس عليهم

\begin{tabular}{|c|c|c|c|c|}
\hline 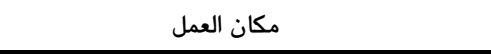 & الاختصاص & اللقب العلمي & 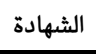 & 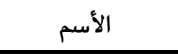 \\
\hline جامعة البصرة/ كلية التربية البدنية وعلوم الرياضة & التدريب الرياضي & 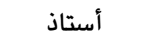 & دكتوراه & عادل مجيد خزعل \\
\hline جامعة البصرة/ كلية التربية البدنية وعلوم الرياضة & التدريب الرياضي & 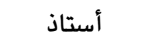 & دكتوراه & حسام محمد جابر \\
\hline جامعة البصرة/ كلية التربية البدنية وعلوم الرياضة & التدريب الرياضي & 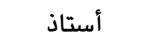 & دكتوراه & محمد عيسى جوي \\
\hline جامعة زاخو/ فاكولتي التربية/ قسم الربية الرياضية & طرائق تدريس & أستاذ مساعد & دكتوراه & محمد مهدي محمد \\
\hline جامعة زاخو/ فاكولتي التربية/ قسم الربية الرياضية & 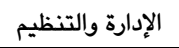 & 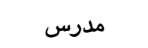 & ماجستير & مفد مظفر محمد \\
\hline
\end{tabular}

الملحق رقم (2) استبيان الاختبارات المهارية الهجومية بكرة السلة

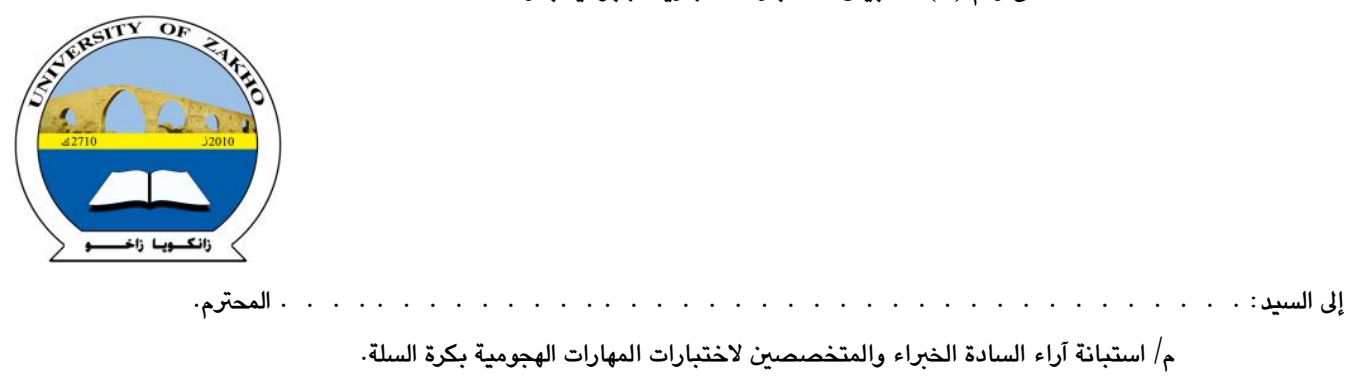
جامعة زاخو
فاكولتي التربية
قسم التربية الرياضية

تحية طيبة:

يروم الباحث إجراء بحثه الموسوم (معالجة المعلومات وعلاقته بأداء المهارات الهجومية بكرة السلة لدى طلاب قسم التربية الرياضية في جامعة زاخو)، ولكونكم من ذوي الخبرة

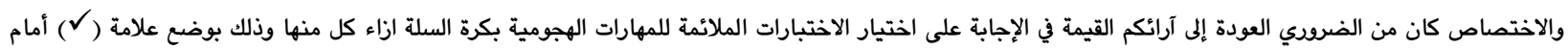

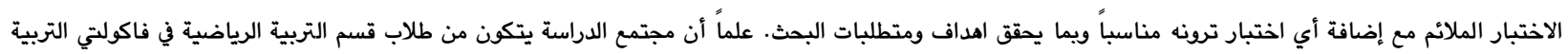
شاكرين تعاونكم معنا خدمةً للبحث العلمي... -

بجامعة زاخو.

الباحث

\begin{tabular}{|l|l|l|}
\hline التصويب & \\
\hline \\
\hline
\end{tabular}


الزاخولي ، علي محمد /حمد / مجلة العلوم الانسانية لجامعة زاخو، مجلد: ، العدد:2 ، ص 307- 326 ، خزيران- 2021.

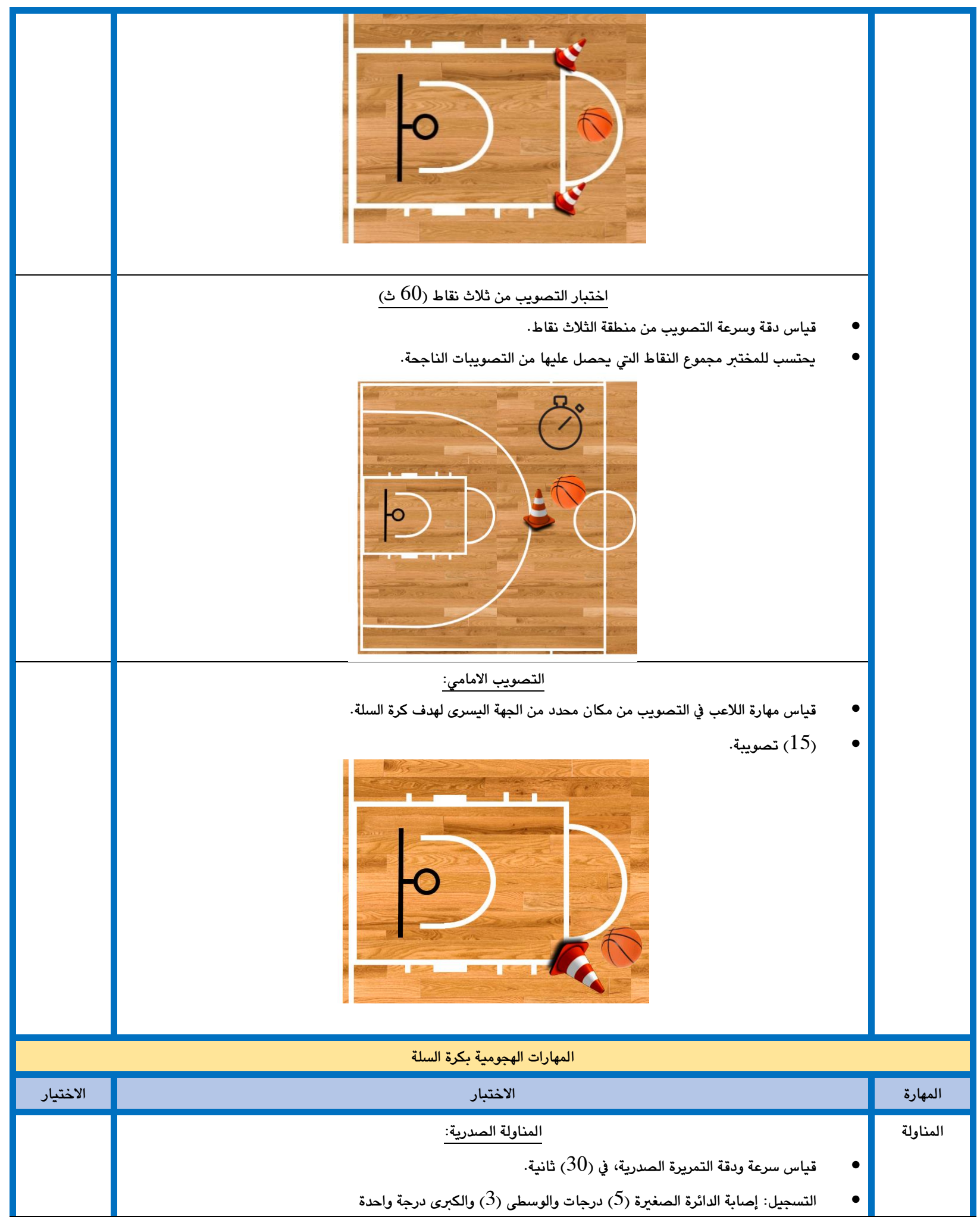


الزاخولي ، علي محمد /حمد / مجلة العلوم الانسانية لجامعة زاخو، مجلد: ، العدد:2 ، ص 307- 326 ، خزيران- 2021.

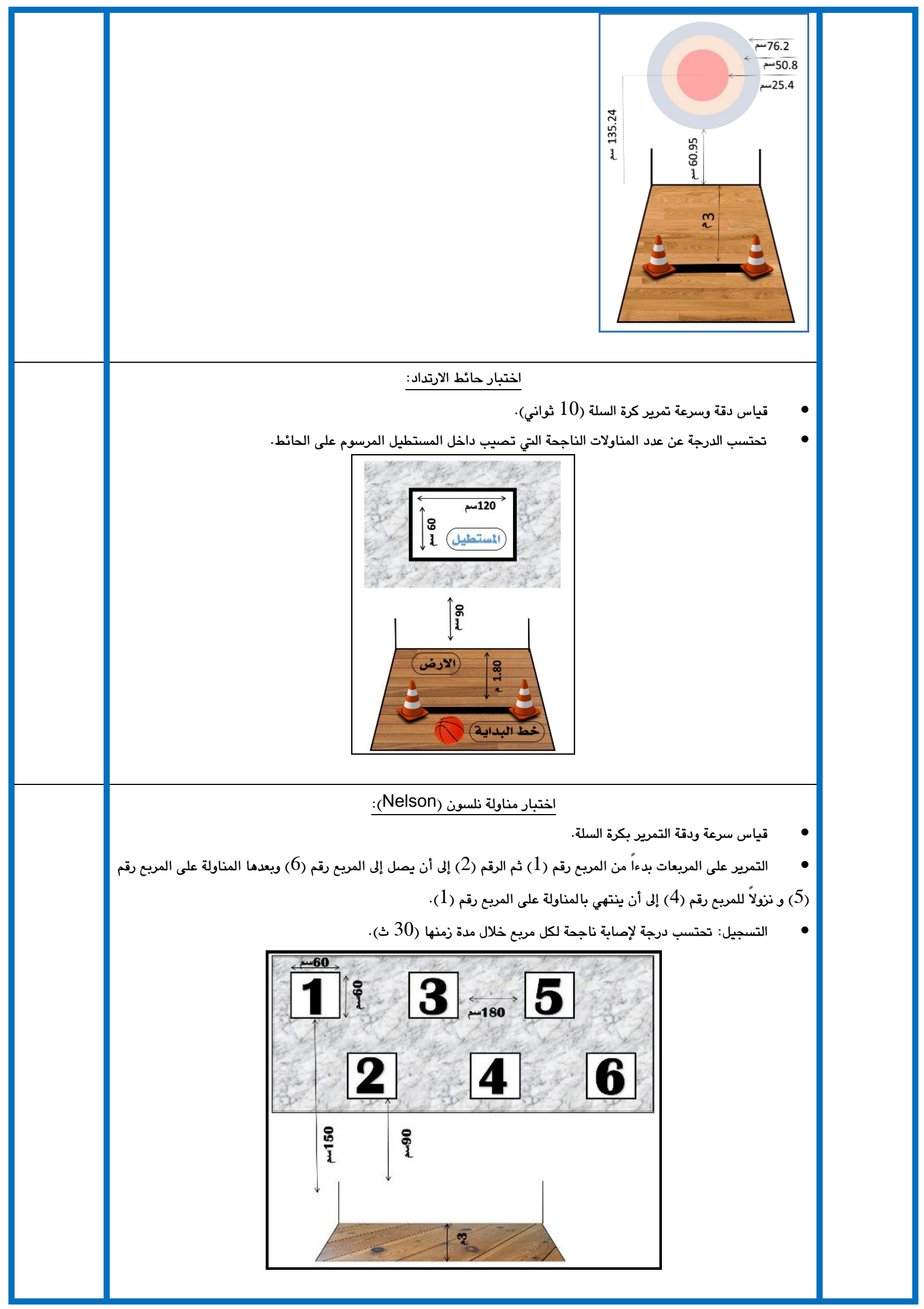


الزاخولي ، علي محمد /حمد / مجلة العلوم الانسانية لجامعة زاخو، مجلد ، ، العدد:2 ، ص 307- 326 ، خزيران- 2021.

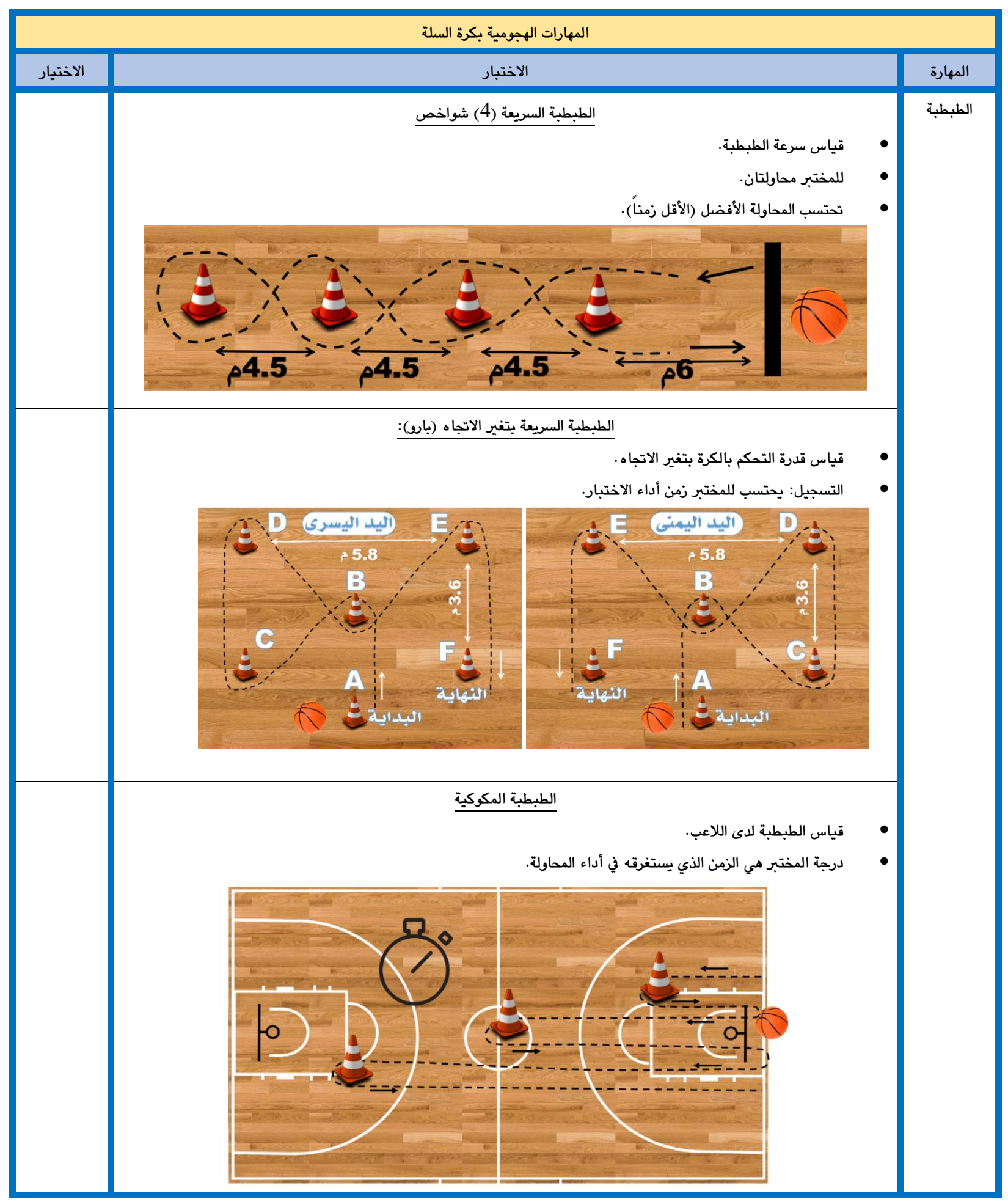

الملحق رقم (3) قائمة أسماء للسادة الخبراء والمتخصصين في مجال كرة السلة التي تم عرض المقياس عليهم

\begin{tabular}{|c|c|c|c|c|}
\hline 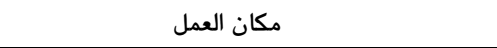 & الاختصاص & اللقب العلمي & 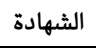 & 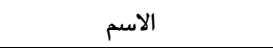 \\
\hline جامعة البصرة/ كلية التربية البدنية وعلوم الرياضة & 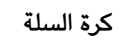 & 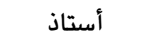 & دكتوراه & حيدر عبد الرزاق كاظم \\
\hline جامعة البصرة/ كلية التربية البدنية وعلوم الرياضة & 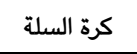 & 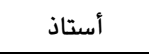 & دكتوراه & عادل ناجي حسن السعدون \\
\hline جامعة البصرة/ كلية التربية البدنية وعلوم الرياضة & 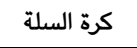 & 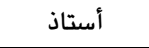 & دكتوراه & قصي فوزي خلف \\
\hline جامعة الموصل/ كلية التربية البدنية وعلوم الرياضة & 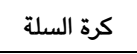 & 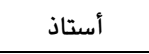 & دكتوراه & هاشم أحمد سلمان \\
\hline جامعة دهوك/ كلية التربية البدنية وعلوم الرياضة & 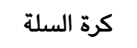 & أستاذ مساعد & دكتوراه & جلال كمال محمد \\
\hline
\end{tabular}




$$
\text { (4) الملحق رقم (1) }
$$

استمارة الاستبيان لمقياس معالجة المعلومات المرسلة للساجة الخبراء والمتخصصين

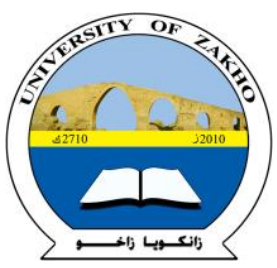

$$
\text { بوتابيَِ هيَذا (الطالب المحترم) }
$$

سلاظــــــــــ

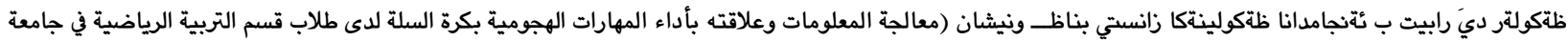

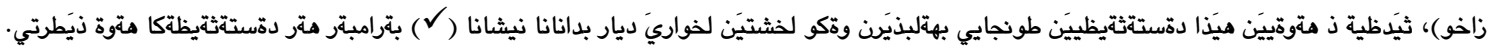

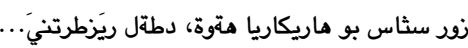

تحية طيبة... يروم الباحث إجراء بحثه الموسوم بـ (معالجة المعلومات وعلاقته بأداء المهارات الهجومية بكرة السلة لدى طلاب قسم التربية الرياضية في جامعة زاخو)، المطلوب من حضراتكم

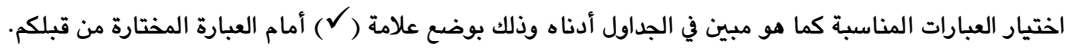
شكرا جزيلا على تعاونكم، مع فائق الاحترام والتقدير...

\begin{tabular}{|c|c|c|c|}
\hline \multicolumn{4}{|c|}{ 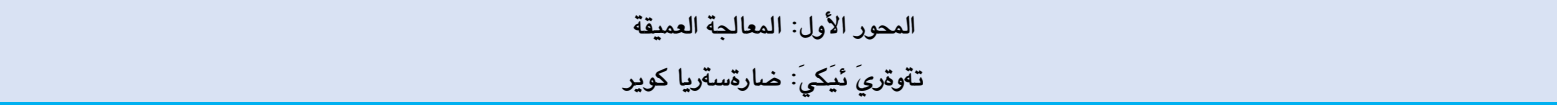 } \\
\hline لا لنطبق عليه & دطنة دطق عليه & الفقرات - برطة & j \\
\hline & & 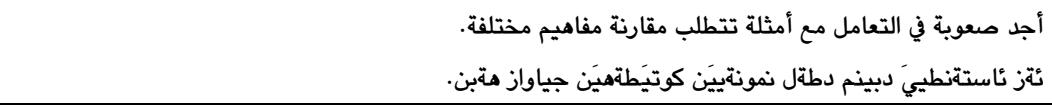 & 1 \\
\hline & & أجد مشقة في التوصل إلى استنتاجات. & 2 \\
\hline & & 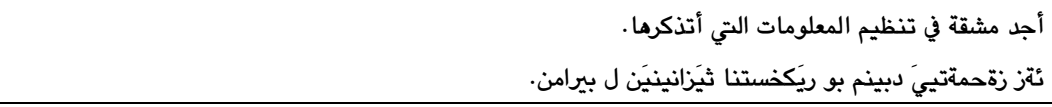 & 3 \\
\hline & & 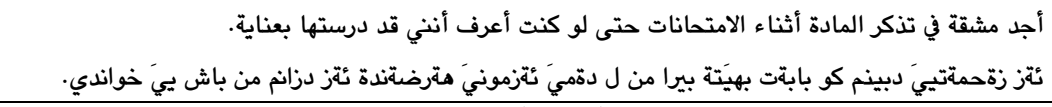 & 4 \\
\hline & & 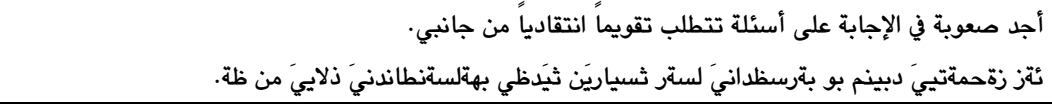 & 5 \\
\hline & & أجيب بشكل جيد في الامتحانات المقالية تتضمن قيامي بمقارنة الأفكار وتوصلني إلى فكرة محددة بخصوصها. & 6 \\
\hline
\end{tabular}




\begin{tabular}{|c|c|c|c|}
\hline & & 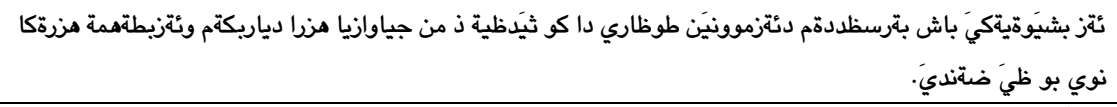 & \\
\hline & & 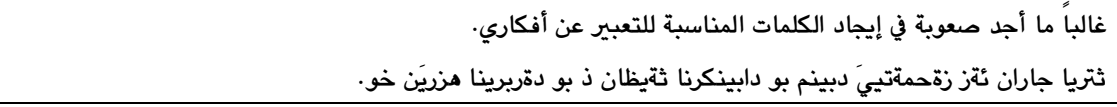 & 7 \\
\hline & & 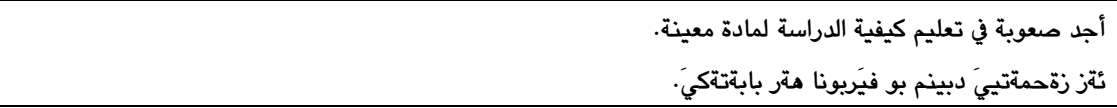 & 8 \\
\hline & & 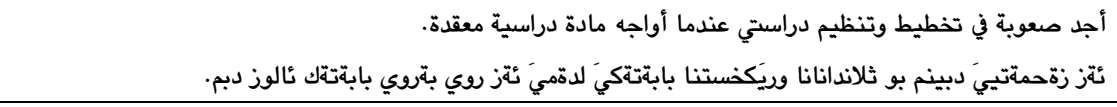 & 9 \\
\hline & & أنةز نمريَن باش أحصل على درجات جيدة على إعداد التقارير. & 10 \\
\hline & & غالباً ما أحفظ عن ظهر قلب المواد التي لا افهمها. & 11 \\
\hline & & 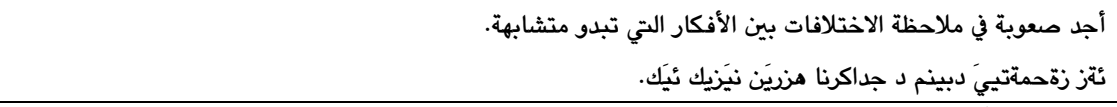 & 12 \\
\hline & & أستطيع عادةً أن اقرد المغزى من وراء الأفلام التي اشاهدها والكتب التي أقرؤها. & 13 \\
\hline & & تفكيري سريع في حل المشكلات التي أواجهها. & 14 \\
\hline & & ثتريا ماموستاييَن من وانسينَ خون محاضراتهم بصورة سريعة. & 15 \\
\hline & & 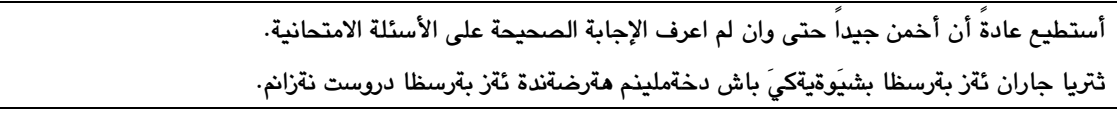 & 16 \\
\hline & & نة بةتي أهمل الاختلافات الموجودة في المعلومات المشتقات من مصادر مختلفة. & 17 \\
\hline & & أقوم بانتقاء وتقييم الأفكار اثناء قراءتي للكتب والمنشورات الأخرى. & 18 \\
\hline
\end{tabular}

\begin{tabular}{|c|c|c|c|}
\hline & & 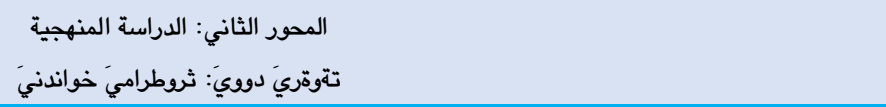 & \\
\hline \multirow[t]{9}{*}{ لا لا تنطبق عليه } & دنطيق عليه & الفقرات - برطة & j \\
\hline & & 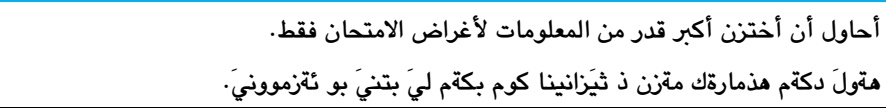 & 1 \\
\hline & & لدي فترات مراجعة أسبوعية منتظمة. & 2 \\
\hline & & 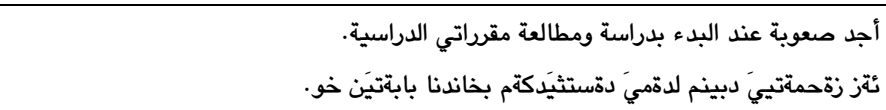 & 3 \\
\hline & & 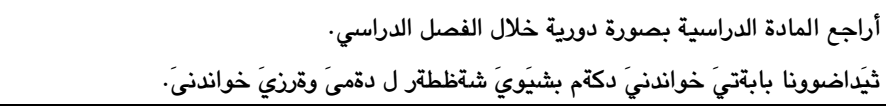 & 4 \\
\hline & & هة احتفظ بجدول يومي لساعات دراستيَ. & 5 \\
\hline & & 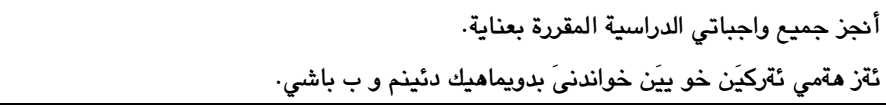 & 6 \\
\hline & & غالباً ما أكتب ملخصاً للمادة التي اقرؤها. & 7 \\
\hline & & أنني أقضي وقتاً في الدراسة أطول من الوقت الذي يقضيه غالبية أصدقائي. & 8 \\
\hline
\end{tabular}




\begin{tabular}{|c|c|c|c|}
\hline & & دةميَنَ ئةز دبورينم بو خواندنى دريَتترن ذ ثتريا هةظظاليَن من. & \\
\hline & & بدةستقي العديد من الملاحظات للمقرر الدراسي من مصادر عدة. & 9 \\
\hline & & غالباً ما أقرأ أكثر مما يعطى لي في الصف. & 10 \\
\hline & & ظة أرجع عادة إلى مصادر متعددة من أجل أن افهم فكرة معينة. & 11 \\
\hline & & 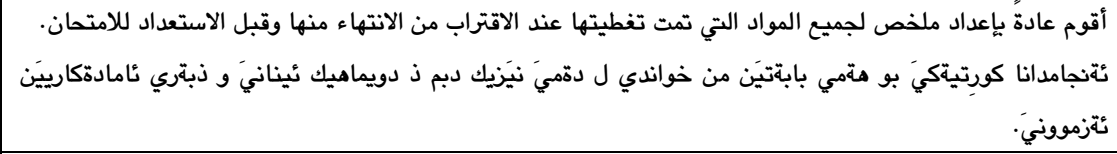 & 12 \\
\hline & & 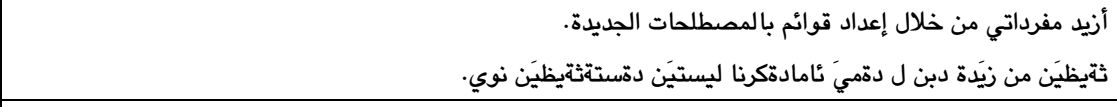 & 13 \\
\hline & & 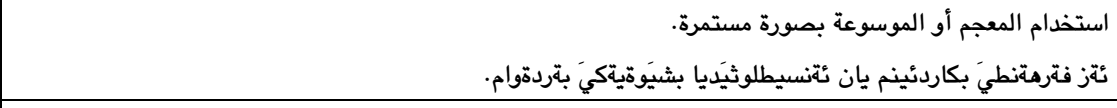 & 14 \\
\hline & & 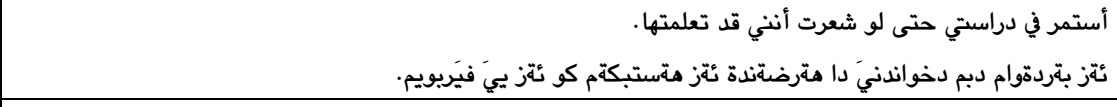 & 15 \\
\hline & & 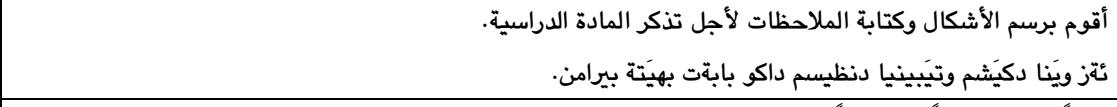 & 16 \\
\hline & & ثالباً ما أبذل جهداً استثنائياً للحصول على كافة التفاصيل المتعلقة بالمادة الدراسية. & 17 \\
\hline & & 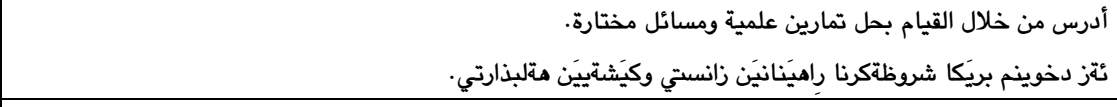 & 18 \\
\hline & & من جهة مكان ثابت في الدراسة. & 19 \\
\hline & & 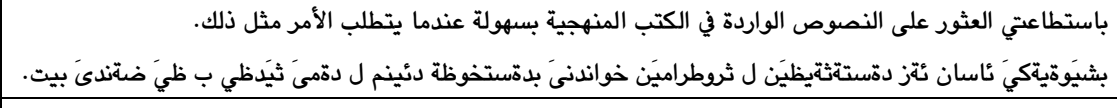 & 20 \\
\hline & & ل دائما أفضل قراءة أصل المقال بدلا من خلاصته. & 21 \\
\hline & & ثةرتةكخانيَ بشيَوةِيةكيَ بةردةوام بكاردئينم. & 22 \\
\hline & & أقة لئوم بإعداد قائمة بالأسئلة المحتملة وإجابتها عندما أقرأ للامتحانات. & 23 \\
\hline
\end{tabular}

\begin{tabular}{|c|c|c|c|}
\hline \multicolumn{4}{|c|}{ 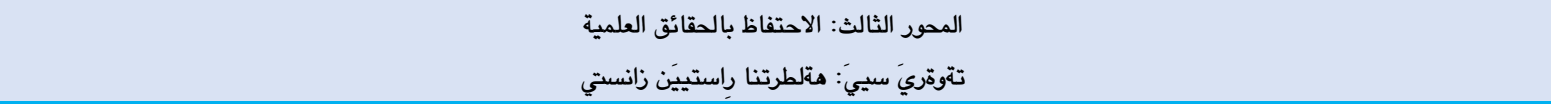 } \\
\hline \multirow[t]{6}{*}{ لا لا تنطبق عليه } & دطنيق عليه & الفقرات - برطة & j \\
\hline & & 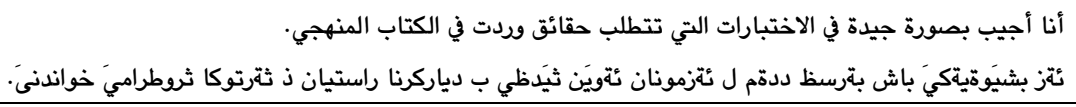 & 1 \\
\hline & & 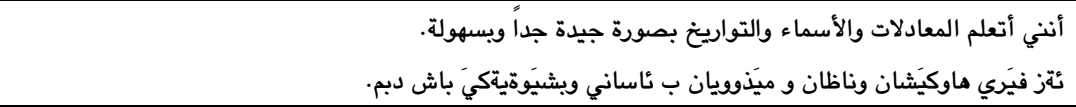 & 2 \\
\hline & & 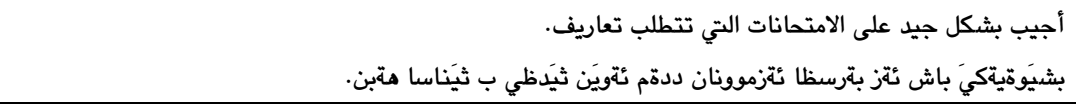 & 3 \\
\hline & & بة إجابتي جيدة في الامتحانات التي تتطلب إكمال الحل والمعلومات الناقصة. & 4 \\
\hline & & اجيد مشقة في تذكر التعاريف. & 5 \\
\hline
\end{tabular}




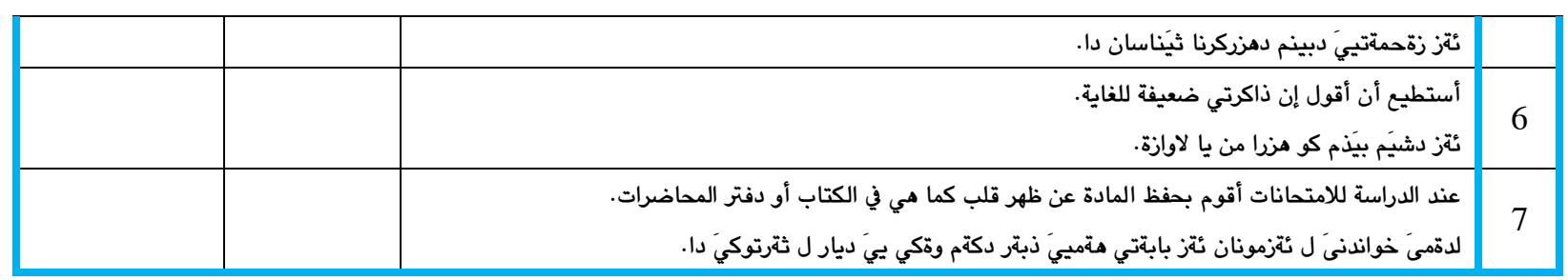

\begin{tabular}{|c|c|c|c|}
\hline \multicolumn{4}{|c|}{ 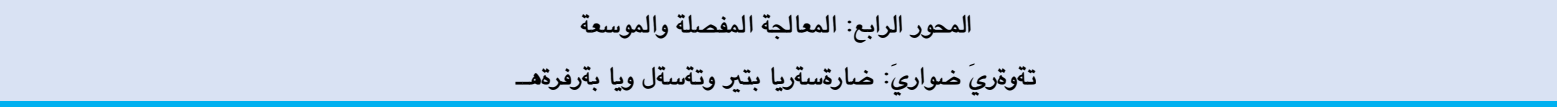 } \\
\hline \multirow[t]{15}{*}{ لا لا تنطبق عليه } & دنطيق عليه & الفقرات - برطة & j \\
\hline & & ل أنني أبحث باستمرار عن الأسباب التي تكمن وراء الحقائقَ. & 1 \\
\hline & & هزبعَني باش من ثالَكار الجيدة أفكر بالأفكار المتشابهة. & 2 \\
\hline & & 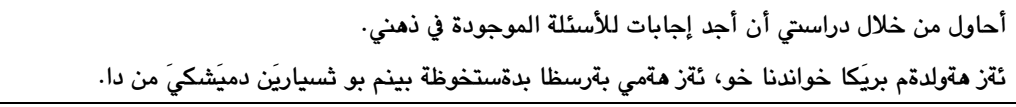 & 3 \\
\hline & & 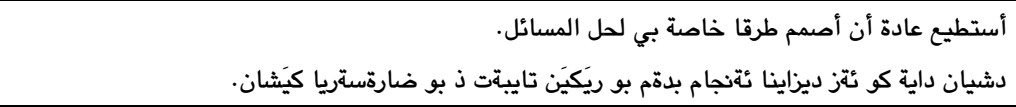 & 4 \\
\hline & & بعد مطالعتي لأية مادة اتأمل وأفكر بعمق في المواضيع التي قرأتها. & 5 \\
\hline & & 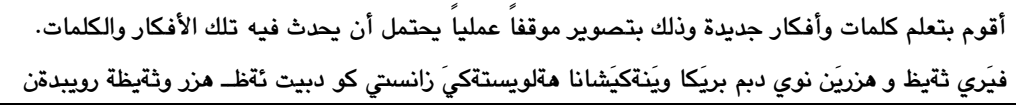 & 6 \\
\hline & & 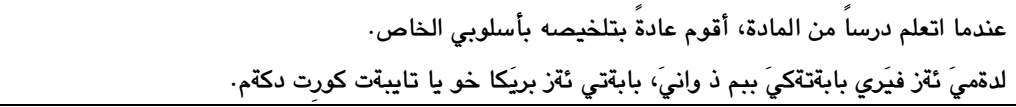 & 7 \\
\hline & & 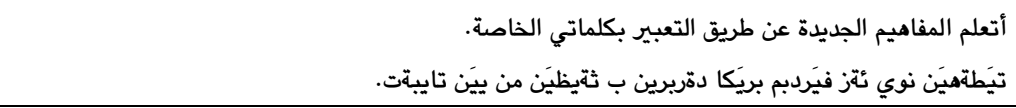 & 8 \\
\hline & & لهائماً تعيش معي الموضوعات التي أدرسها خلال اليوم. & 9 \\
\hline & & 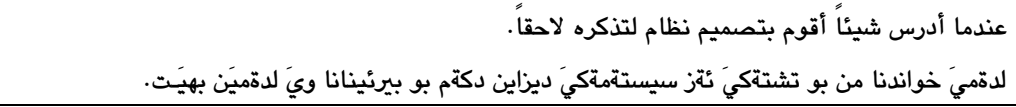 & 10 \\
\hline & & 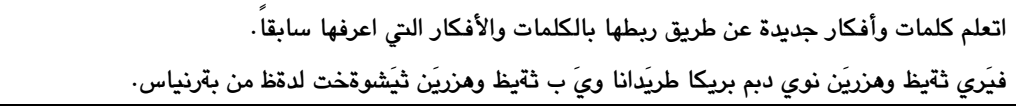 & 11 \\
\hline & & 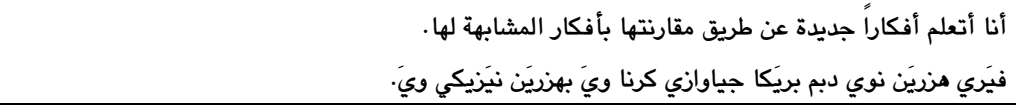 & 12 \\
\hline & & رأعمل على تحويل الحقائق على قوانين استخلصها من خبرتي. & 13 \\
\hline & & 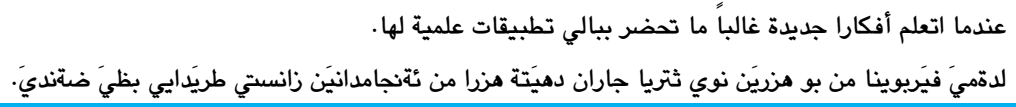 & 14 \\
\hline
\end{tabular}

الملحق رقم (5) اختبار التصويب الامامي من القفز

$$
\text { اسم الاختبار: التصويب الأمامي من القفز. }
$$

الهدف من الاختبار: قياس دقة التهديف لدى اللاعب من القفز على امتداد خط الرمية الحرة.

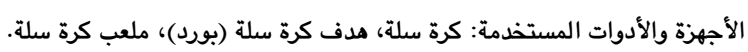


طريقة الأداء: يقوم المختبر بالتهديف على السلة من مكان خارج منطقة الرمية الحرة وعلى امتداد منطقة الرمية الحرة وعند تقاطعه مع الدائرة ويجب تثبيت الاشارة في المنطقة

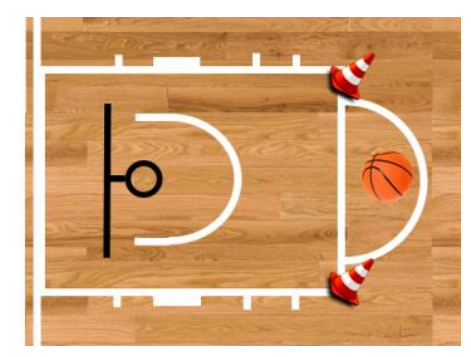

المحددة للتهديف. كما في الشكل (1).

شكل (1) يوضح اختبار التصويب الأمامي من القفز

شروط الاختبار: من الممكن ان يقوم المختبر بالتهديف بيد واحدة أو باليدين معا.

للمختبر 10 محاولات يتم ادائها في المجموعتين كل مجموعة 5 رميات.

يسمح للمختبر قبل بدء الاختبار بأداء بعض الرميات على سبيل التجربة.

طريقة التسجيل: تحسب مجموع درجات التصويبات الناجحة.

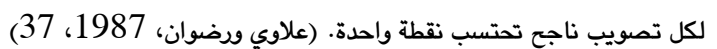

الملحق رقم (6) اختبار المناولة الصدرية

اسم الاختبار: اختبار المناولة الصدرية

الهدف من الاختبار: قياس سرعة ودقة المناولة الصدرية في (30) ثانية. الأجهزة والأدوات المستخدمة: حائط ألمس، كرة سلة، ساعة توقيت.

طريقة الأداء: يقف المختبر خلف الخط المرسوم على الأرض ويبعد عن الحائط بمقدار 10 أقدام (3م).

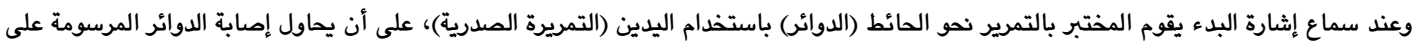

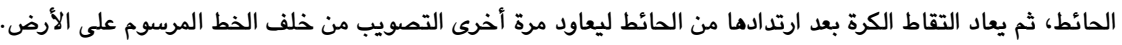

يكرر الأداء بأسرع ما يمكن لأداء أكبر عدد من المناولات في 30 ثانية. شروط الأداء: الإصابات خلال الـ 30 ثانية. يجب أن تكون قدما المختبر خلف الخط المرسوم على الأرض سواء عند التمرير أو الاستلام.

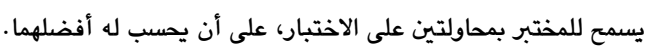
الخطوط المرسومة على الحائط تعتبر داخل مقاييس الدوائر.

عرض الخط نصف بوصة (1.3سم).

يرسم خط على الأرض وعلى بعد 10 أقدام (3م) من الحائط، ويرسم على الحائط ثلاث دوائر متداخلة ذات مركز واحد قطر كل منهما هو: الكبرى 30 بوصة

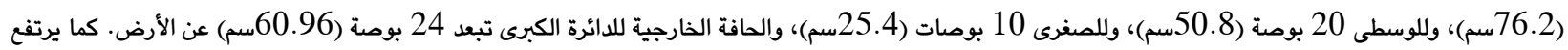

مركز الدائرة الصغرى عن الأرض مقدار أربعة أقدام وست بوصات (135.24سم)، وسم)، كما في الشكل (2).

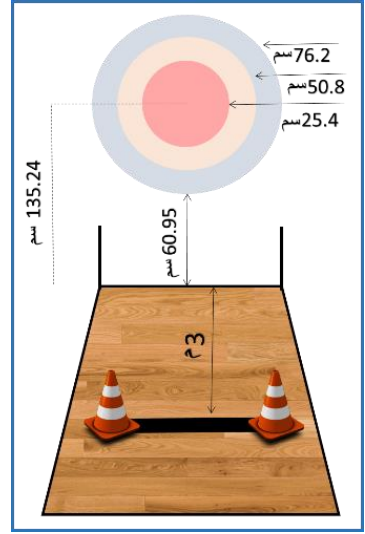

شكل (2) يوضح اختبار المناولة الصدرية

طريقة التسجيل:

يحسب النقاط لكل إصابة صحيحة يقوم بها المختبر خلال الثلاثين ثانية المقررة للاختبار، وذلك وفقاً للشروط التاليـة:

إذا اصابت الكرة الدائرة الصغيرة يحصل المختبر على 5 درجات. 
الزاخولي ، علي محمد /حمد / مجلة العلوم الانسانية لجامعة زاخو، مجلد:9 ، العدد:2 ، ص 307- 326 ، خزيران- 2021.

$$
\begin{aligned}
& \text { ب- إذا اصابت الكرة الدائرة المتوسطة يحصل المختبر على } 3 \text { درجات. } \\
& \text { ج- إذا الصابت الكرة الدائرة الكبرى يحمل المختبر على درجة واحدة. }
\end{aligned}
$$

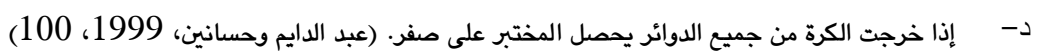

$$
\begin{aligned}
& \text { الملحق رقم (7) اختبار المناولة الصدرية }
\end{aligned}
$$$$
\text { اسم الاختبار: اختبار الطبطبة بين (4) شواخص. }
$$$$
\text { الهدف من الاختبار: اختبار الطبطبة بين (4) شواخص ذهاباً واياباً بأقل وقت ممكن. }
$$$$
\text { الأجهزة والأدوات المستخدمة: شواخص عدد (4)، ساعة توقيت، كرة السلة، ملعب كرة السلة. }
$$

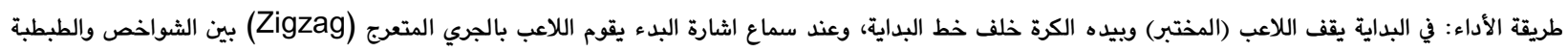
المستمرة بالكرة.

شروط الاختبار:

• يتم ترتيب الشواخص كما مبين في الشكل أدناه، مع رسم خط البداية الذي يبعد عن الشاخص الاول بمسافة (6م)، في حين ان المسافة بين الشواخص الباقية قدرها

(3.5) (3.5)، كما في الشكل (3).

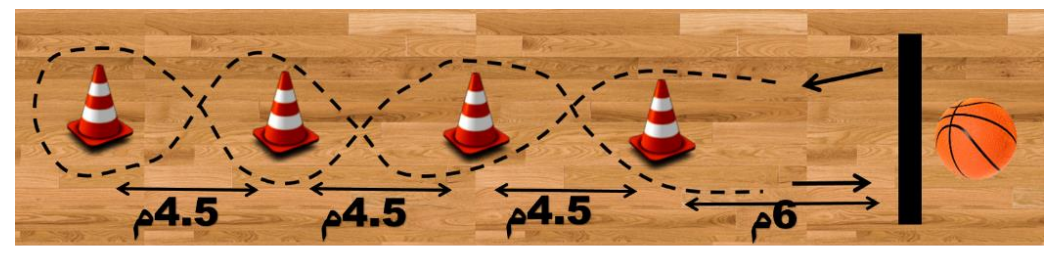

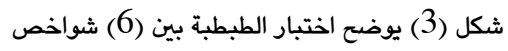

• ان يصل المختبر الى خط النهاية ذهابا وايابا الى ان يتجاوذ خط البداية. وعلى الميقاتي في هذه الحالة حساب الزمن الذي استغرقته هذه المحاولة أي (البداية - النهاية

يتم اعتماد الزمن الافضل لأحدى المحاولتين. (عبد الدايم وحسانين، 1999، 129 لمنين. 


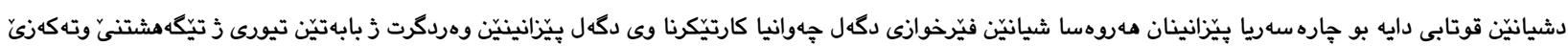

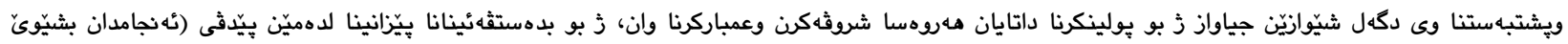

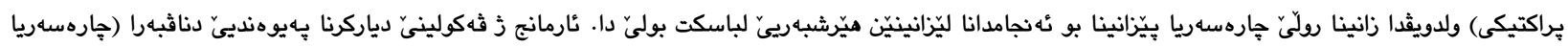

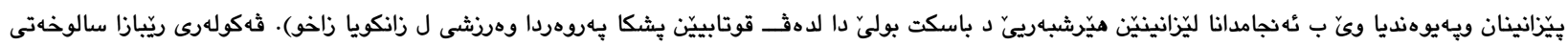

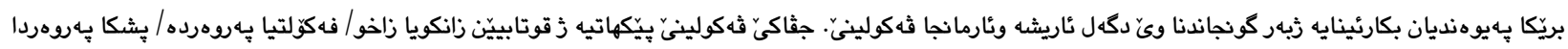

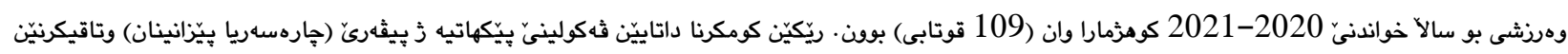

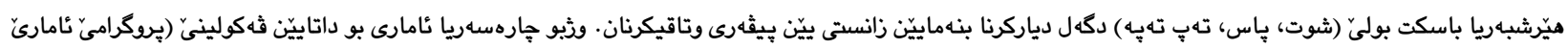

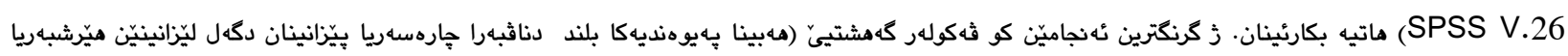

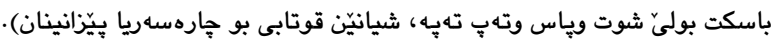

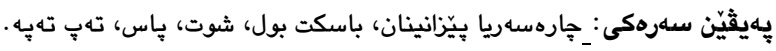

Information processing and its relationship to the performance of offensive skills in basketball for students of the Department of Physical Education at the University of Zakho

\begin{abstract}
:
The importance of the current study In students' ability to process information and also the learner's ability to work with the information he receives from theoretical lessons in understanding, concentration, remembering and perception, and his reliance on different patterns in order to classify this information as well as analyze it and then store it in order to be retrieved meaning it is practically applied when needed.And then learn the role of information processing in the performance of offensive skills with basketball. The aim of the study is to identify the relationship (Information processing and its correlation with the performance of offensive basketball skills among students of the Physical Education Department at the University of Zakho). The researcher used the Descriptive Method in a correlational method to suit it with the objectives and the problem of the study, and the study population consisted of (109 students) at the University of Zakho/ Faculty of Education/ Department of Physical Education for the academic year 2020-2021. As for the methods of data collection for the study, it included scale (Information Processing) and offensive skills tests for basketball (Shooting, Passing, Dribbling) with Criteria finding in terms of (Validity, Reliability, Objectivity) for the scale as well as for skill tests. For the statistical treatment of data, the researcher used the SPSS V.26 statistical bag. The most important conclusions reached by the researcher are (the existence of a high correlation between information processing and the skills of Shooting Passing Dribbling for basketball, the ability of students to process information).
\end{abstract}

Keywords: Information Processing, Basketball, Shooting, Passing, Dribbling. 